\title{
ANALISIS STRUKTUR, PERILAKU, DAN KINERJA INDUSTRI POPOK BAYI SEKALI PAKAI DI INDONESIA
}

\author{
Lulu Sugiarto \\ Program Studi Magister Manajemen Universitas Tarumanagara \\ lcioust@gmail.com
}

\begin{abstract}
The purpose of this research is to is to determine how is the structure, conduct, and performance of baby diaper industry in Indonesia. The paradigm known as Structure Conduct - Performance (SCP) shown those three aspects are integrally related.The type of data at this research is secondary data which is collection from Badan Pusat Statistik (BPS), annual report of baby diaper industry published by Nielsen from 2012 to 2016 and literature related to this study. The research methodology applies descriptive analytical method in describing SCP of baby diaper industry in Indonesia systematically and accurately. The analysis on structure refer to elucidation on products, industry concentration ratio (CR), Herfindahl-Hirschman Index (HHI), technology, demands and market condition and ease of entry and exit (Porter Five Forces Model). The conduct analysis refer to pricing, product, distribution and promotion strategies. The performance analysis refers to industrial growth and corporate social responsibility (CSR). The result shows that the market structure is quite stable. CR4 calculation indicating oligopoly market. HHI calculation is over 2.500 representing highly concentrated exposed to high technology. Five Porter Forces showed fives strength analysis from threat of entry, power of suppliers, power of buyers, threat of substitutes and rivalry among existing competitor. Price determination, product development, strengthen distribution line, and aggressive advertising and promotion are part of the strategies. Moreover, there is high tendency of merger and supported by managerial implication. From financial perspective, mamy poko remains on top.
\end{abstract}

Keywords : SCP, Baby Diaper Industry, CR, HHI, Technology, Merger Activity, Porter Five Forces Model, Pricing, Product, Distribution, Promotion, Growth, CSR.

\section{PENDAHULUAN}

Sektor industri mempunyai peranan penting dalam perekonomian Indonesia. Secara umum sektor ini memberikan kontribusi yang besar dalam pembentukan produk domestik bruto nasional dan penerimaan devisa. Sektor industri diyakini sebagai sektor yang dapat memimpin sektor-sektor lain dalam sebuah perekonomian menuju kemajuan. Produk industri selalu memiliki terms of trade yang tinggi serta menciptakan nilai tambah yang lebih besar dibandingkan produk-produk lain. Hal ini disebabkan karena sektor industri memiliki variasi produk yang sangat beragam dan mampu memberikan manfaat yang tinggi kepada pemakainya (Dumairi, 2000).

Jumlah penduduk dan tingkat pertumbuhannya akan sangat mempengaruhi jumlah konsumsi nasional suatu Negara, Menurut CIA World Factbook Tahun 2016 Indonesia merupakan Negara yang menduduki urutan keempat di dunia dengan jumlah penduduknya sebanyak 258.316.051 jiwa. Tersebar diseluruh wilayah kepulauan Republik Indonesia dengan sebagian besarnya berada di Pulau Jawa sebanyak 56,82\%. (Sumber : www.bps.go.id) 


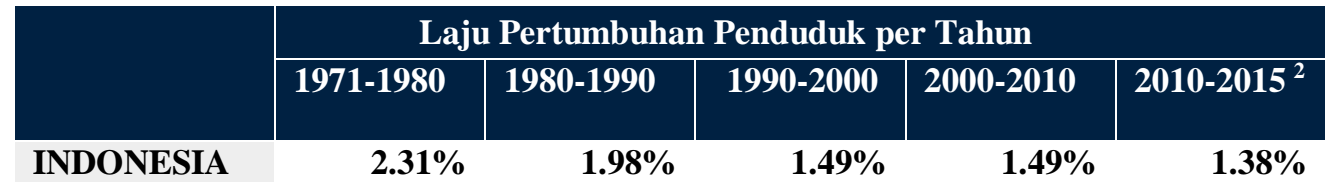

Sumber : www.bps.go.id

Banyaknya jumlah penduduk dengan tingkat pertumbuhan yang tinggi menjanjikan peluang bisnis yang prospektif bagi industri popok bayi sekali pakai, didukung dengan era modernisasi dimana masyarakat cenderung memilih sesuatu yang cepat dan praktis, masyarakat lebih memilih sesuatu yang praktis dan higienis dan menggunakan popok bayi sekali pakai, keseluruhan faktor tersebut mendukung pertumbuhan yang signifikan terjadi pada industri popok bayi sekali pakai di Indonesia. PT. Unicharm Indonesia dengan merk dagangnya Mamy Poko menjadi pemimpin pasar, dengan perolehan pertumbuhan yang signifikan di pasar Indonesia selama periode tahun 2002 - 2015. Pertumbuhan yang dicapai sekaligus menggambarkan industri yang sehat dan terus berkembang, rekaman kesuksesan yang diperoleh PT. Unicharm Indonesia menjadikan industri popok bayi sekali pakai sangat menarik dan patut dilirik oleh banyak pengusaha lokal maupun asing.

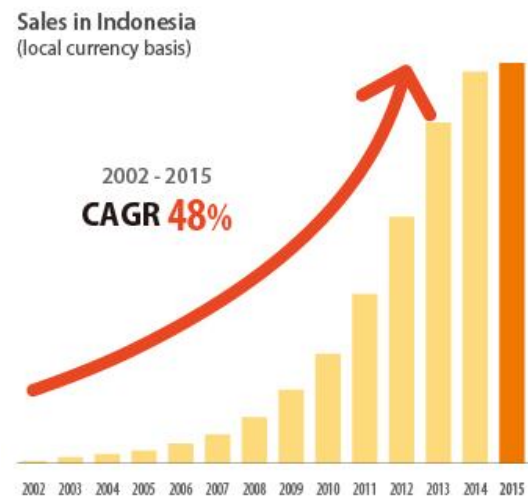

Sumber : $\underline{\text { www.unicharm.co.jp }}$

Ladang subur industri popok bayi sekali pakai di Indonesia menciptakan arena persaingan yang ketat bagi pelaku industri. Hal ini secara langsung akan memengaruhi struktur, perilaku dan kinerja dari suatu industri. Ketatnya persaingan antar perusahaan popok bayi sekali pakai menyebabkan para produsen lebih mencermati keadaan pasar, misalnya dengan mencermati segmentasi produk berdasarkan umur, berat badan, ukuran, dan status ekonomi. Kondisi permintaan pasar terhadap kualitas popok bayi sekali pakai yang nyaman dan aman dipakai mendorong para produsen untuk melakukan pengembangan dan peningkatan kualitas produk, memproduksi berbagai varian produk yang dikombinasikan dengan beberapa faktor produksi untuk menetapkan harga agar sesuai sasaran pasar yang dibidik . Oleh karena itu kajian yang kali ini dilakukan mengenai analisis industri popok bayi sekali pakai di Indonesia merupakan hal yang cukup penting.

\section{TINJAUAN PUSTAKA}

\section{Pendekatan Structure-Conduct-Performance (SCP)}

Mason dan Bain dalam Lipczynski (2005) menjelaskan struktur pasar mempengaruhi perilaku perusahaan, dari perilaku ini akan menimbulkan strategi untuk mencapai kinerja perusahaan yang lebih baik.

Struktur Pasar (Structure) 
Struktur pasar dapat menunjukan lingkungan persaingan antar penjual dan pembeli melalui proses terbentuknya harga dan jumlah produk yang ditawarkan dalam pasar (Jaya, 2008). Struktur pasar memiliki beberapa elemen-elemen penting yaitu pangsa pasar, konsentrasi dan hambatan masuk pasar. Elemen-elemen tersebut akan menggambarkan ukuran perusahaan-perusahaan yang bersaing di dalam suatu pasar.

\section{Perilaku (Conduct)}

Perilaku pasar dimaksudkan sebagai pola tanggapan dan penyesuaian yang dilakukan suatu perusahaan di dalam pasar untuk mencapai tujuannya. Perilaku pasar terkait dengan tindakan apa yang harus dilakukan suatu perusahaan dalam menghadapi pesaingnya terhadap harga, tingkat produksi, kualitas produk, tindakan promosi, dan hal penting lainnya yang berkaitan dengan kegiatan operasional perusahaan (Greer, 1992).

\section{Kinerja (Performance)}

Kinerja merupakan hasil kerja yang dipengaruhi oleh struktur dan perilaku industri. Pada dasarnya, kinerja mengukur empat hal, yaitu allocation efficiency, income distribution, technical efficiency, dan technological progress. Menurut Lipezynski (2005), indikator kinerja meliputi : Profitabilitas (Tingkat Keuntungan), Pertumbuhan, Kemajuan Teknologi, Efisiensi Produksi dan Alokasi.

\section{Corporate Social Responsibility (CSR)}

Corporate Social Responsibility (CSR) merupakan konsep yang telah lama digunakan oleh perusahaan dan terus mengalami perkembangan dalam implementasinya. Pada masa lalu, kinerja perusahaan dilihat berdasarkan perspektif pemilik dan aspek keuangan. Sekarang terjadi perubahan dimana stakeholder mulai menyadari dan mengerti akan akibat kegiatan bisnis terhadap lingkungan sekitar perusahaan (Lawrence, 2011).

\section{Hubungan Structure, Conduct, dan Performance}

Struktur pasar akan mempengaruhi perilaku pasar terutama dalam hal sikapnya terhadap kebijakan harga, strategi pengembangan usaha serta strategi dalam produk. Selanjutnya struktur dan perilaku yang dilakukan oleh perusahaan akan mempengaruhi kinerja dalam perekonomian. Menurut Baye (2010) Structure dari suatu industri mengacu pada faktor-faktor seperti teknologi, konsentrasi, dan kondisi pasar. Conduct mengacu pada bagaimana perusahaan berperilaku di pasar, yaitu melibatkan keputusan penetapan harga, keputusan iklan, keputusan untuk melakukan $\mathrm{R} \& \mathrm{D}$, dan keputusan untuk melakukan merger, sedangkan performance mengacu kepada profit dan kesejahteraan social. Paradigma SCP melihat ketiga aspek ini saling memiliki keterkaitan satu sama lain.

\section{METODOLOGI PENELITIAN}

Penelitian ini bersifat kualitatif dengan menggunakan analisa deskriptif. Penelitian ini menekankan pada penjabaran sekaligus analisa data-data sekunder yang akan mendukung explanatory research mengenai industri popok bayi di Indonesia yang mencakup struktur pasar, perilaku, dan kinerjanya. Batasan periode yang diteliti adalah selama 5 tahun. Keseluruhan data diambil sejak tahun 2012 sampai dengan tahun 2016.

Jenis dan sumber data yang digunakan dalam penelitian ini adalah data sekunder, diperoleh dari literature selama perkuliahan dan literature lainnya dari berbagai perpustakaan yang ada di Jakarta. Selain itu, ada juga jurnal-jurnal publikasi di internet, data dari beberapa website perusahaan terkait, data publikasi Badan Pusat Statistik, laporan industri terkait yang diterbitkan oleh The Nielsen Company Indonesia, serta data dari beberapa artikel baik yang didapat melalui media online maupun offline. 


\section{Kerangka Penelitian}

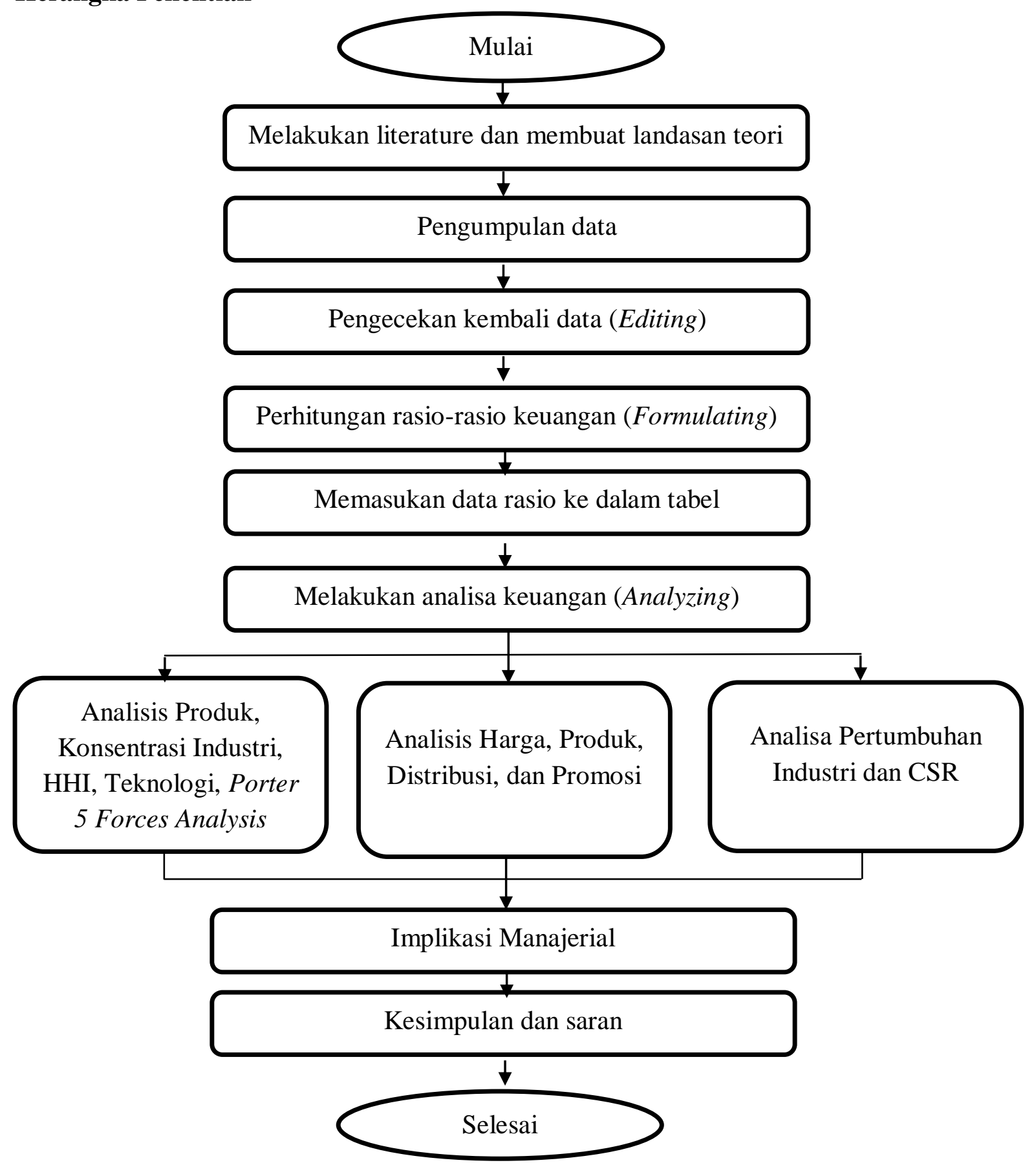

\section{ANALISIS DAN BAHASAN TEMUAN}

Struktur, Perilaku, dan Kinerja merupakan cara yang digunakan untuk melihat kondisi pasar dan persaingan dalam industri, struktur pasar akan menentukan perilaku perusahaan, yang pada akhirnya dapat mempengaruhi kinerja pasar.

\section{A. Struktur Pasar}

Struktur pasar biasanya dilihat dari jumlah pelaku pasar dan pangsa pasarnya. Produk ataupun teknologi yang digunakan juga dapat menjadi satu acuan untuk melihat struktur pasar. Sementara itu, hambatan masuk dan keluar pasar dapat dijadikan pedoman untuk menentukan struktur pasar. Meskipun demikian biasanya dalam literatur sering digunakan Concentration Ratio dan Herfindahl Hirschman Index untuk mengukur segementasi pasar. 
Rasio Konsentrasi 4 Perusahaan Terbesar

\begin{tabular}{|c|c|}
\hline TAHUN & CR 4 \\
\hline 2012 & $91,9 \%$ \\
\hline 2013 & $92,8 \%$ \\
\hline 2014 & $92,7 \%$ \\
\hline 2015 & $90,4 \%$ \\
\hline 2016 & $89,1 \%$ \\
\hline
\end{tabular}

Sumber : Nielsen, diolah

PT. Unicharm Indonesia menjadi pemimpin pasar dengan perolehan pangsa pasar diatas 50\% setiap tahunnya. Konsentrasi pasar popok bayi sekali pakai relatif tinggi berkisar di angka 90\%. Dari data tersebut diatas, dapat disimpulkan bahwa industri popok bayi sekali pakai masuk kedalam pasar oligopoli.

Herfindahl Hirschman Index (HHI)

\begin{tabular}{|l|r|r|r|r|r|}
\hline \multicolumn{1}{|c|}{ NAMA PERUSAHAAN } & \multicolumn{1}{c|}{$\mathbf{2 0 1 2}$} & \multicolumn{1}{c|}{$\mathbf{2 0 1 3}$} & \multicolumn{1}{c|}{$\mathbf{2 0 1 4}$} & \multicolumn{1}{c|}{$\mathbf{2 0 1 5}$} & \multicolumn{1}{c|}{$\mathbf{2 0 1 6}$} \\
\hline Unicharm Indonesia & $2.735,3$ & $3.819,2$ & $4.083,2$ & $3.868,8$ & $3.214,9$ \\
\hline Softex Indonesia & 686,4 & 384,2 & 302,8 & 306,3 & 372,5 \\
\hline Procter and Gambler & 79,2 & 67,2 & 77,4 & 27,0 & 30,3 \\
\hline Zensei & 20,3 & 10,2 & 6,8 & 4,0 & 1,2 \\
\hline Multi Duta Utari & 0,5 & 3,6 & 1,7 & 0,5 & 1,4 \\
\hline Aman Indah Makmur & 1,0 & 0,8 & 1,7 & 1,7 & 2,6 \\
\hline Kao & 0,1 & 0,0 & 0,5 & 30,3 & 57,8 \\
\hline DSG International Ltd & 0,1 & 0,1 & 0,5 & 3,6 & 4,8 \\
\hline Elleair International co Ltd & 0,0 & 0,0 & 0,4 & 3,2 & 9,0 \\
\hline Lain-Lain & 33,6 & 13,7 & 7,3 & 3,6 & 3,2 \\
\hline Total & $3.522,9$ & $4.285,5$ & $4.474,9$ & $4.245,4$ & $3.694,4$ \\
\hline
\end{tabular}

Sumber : Nielsen, diolah

Hasil perhitungan HHI diatas menyimpulkan bahwa industri popok bayi sekali pakai berada dalam pasar dengan konsentrasi tinggi karena nilai HHI setiap tahunnya masih diatas angka 2.500 yang mencerminkan bahwa pasar yang sangat terkonsentrasi.

\section{Produk}

Menurut riset yang dilakukan Nielsen (2016), popok bayi sekali pakai tipe celana lebih diminati, ditandai dengan sales trend yang mengalami peningkatan dari tahun ke tahun, sementara jenis popok tipe perekat mengalami yang sebaliknya :
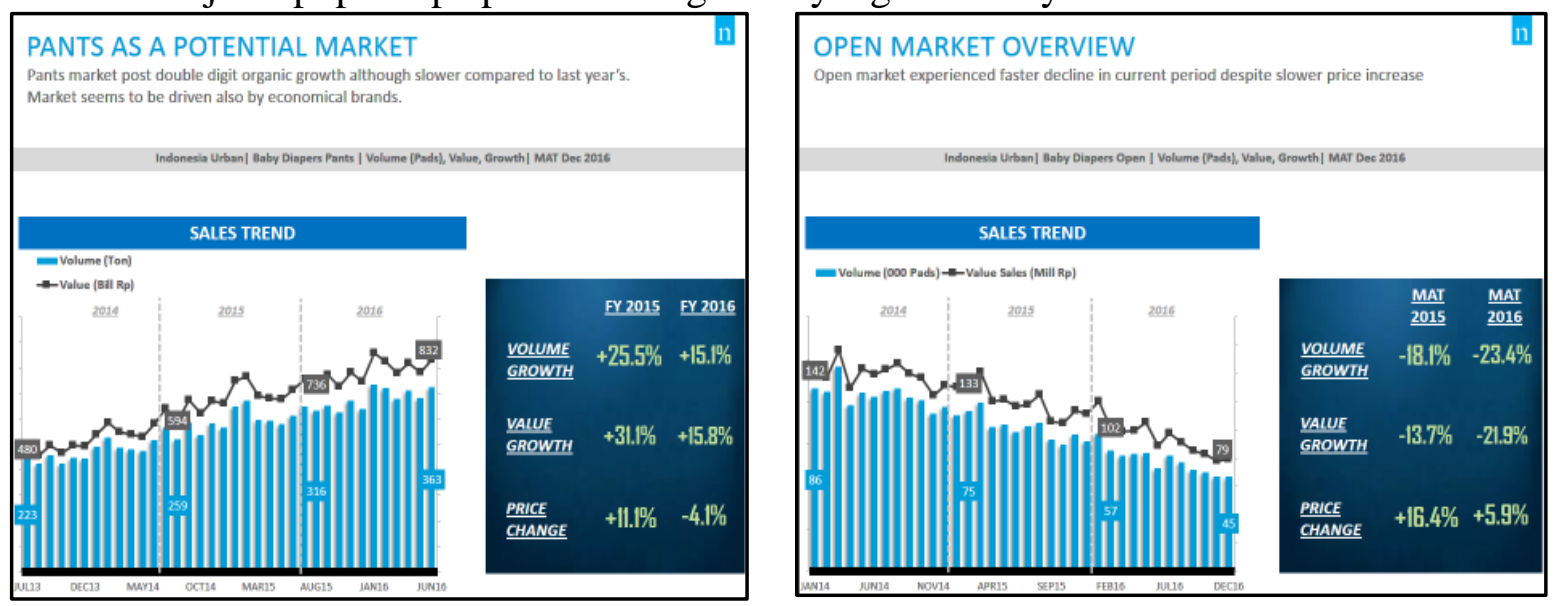

Berdasarkan ukuran, kebanyakan konsumen membeli ukuran medium (M) dan large (L), namun besarnya kemungkinan pembelian produk pertama yang dilakukan konsumen adalah dengan ukuran small (S) atau extra small (XS) untuk bayi yang baru lahir, dan ada 
kecenderungan konsumen akan membeli kembali merek yang sama pada pembelian selanjutnya ketika puas dengan produk pertamanya, sehingga popok bayi ukuran kecil dapat menunjang penjualan popok bayi ukuran lanjutan, beberapa produsen yang sadar akan besarnya potensi produk new born akan memberikan perhatian khusus dalam pengembangan produk ukuran kecilnya.

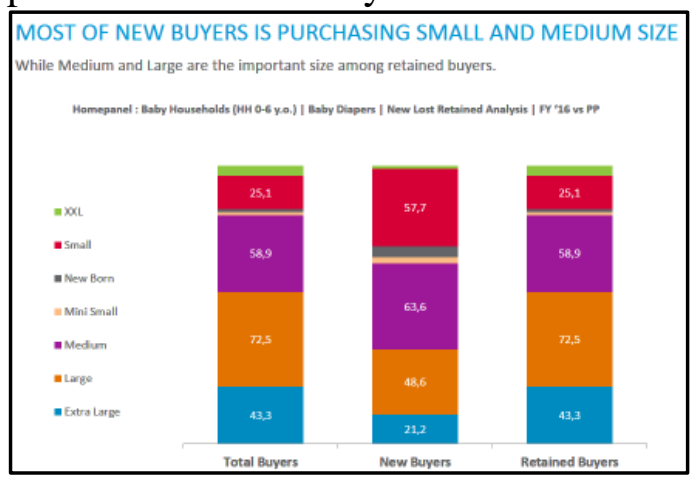

\section{Teknologi}

Perusahaan popok bayi sekali pakai dituntut untuk melakukan inovasi yang berlandaskan riset dan pengembangan yang kuat untuk memenuhi keinginan konsumennya yang beragam mulai dari kelompok ekonomis sampai dengan premium.

Beragam teknologi yang digunakan dan dikembangkan oleh masing-masing perusahaan produsen popok bayi sekali pakai biasanya dilakukan oleh produsen besar yang telah memiliki produk yang cukup kuat di pasar, karena kegiatan pengembangan dan penelitian dalam rangka menemukan teknologi baru ini membutuhkan waktu dan biaya yang relatif besar, bagi perusahaan besar biasanya memiliki divisi khusus penelitian dan pengembangan, sementara produsen kecil tidak memungkinkan untuk melakukannya.

Teknologi yang dikembangkan pada akhirnya akan mempengaruhi pangsa pasar perusahaan, produk dengan teknologi terbaru akan memperbaiki atau menggantikan teknologi lama yang dianggap masih memiliki kekurangan, dengan pengembangan teknologi yang dilakukan kualitas produk akan semakin baik sehingga menambah nilai produk, sehingga mampu mendorong pengambilan keputusan konsumen untuk membelinya. Akibatnya sebagian besar pangsa pasar hanya diperoleh oleh produsen besar saja selama bertahun-tahun, karena keterbatasan teknologi yang digunakan oleh produsen kecil.

\section{Kemudahan Masuk dan Keluar}

Dari analisa 5 kekuatan Porter diketahui bahwa persaingan di dalam industri cukup tinggi, kekuatan ancaman masuk yang rendah, daya tawar pemasok yang tinggi, daya tawar pelanggan yang tinggi, dan ancaman produk pengganti yang rendah.

\section{B. Perilaku Pasar}

Ada beberapa indikator perilaku pasar yang sering digunakan selama ini, antara lain penetapan harga, penelitian dan pengembangan, distribusi, iklan dan promosi. Analisa perilaku pasar dapat dilihat dari beberapa hal sebagai berikut :

\section{Strategi Penetapan Harga}

Persaingan yang ketat akan meningkatkan pasokan persediaan di dalam pasar, sehingga akan membentuk suatu persaingan harga yang kompetitif. Pilihan produk yang beragam dengan harga terjangkau sebagai akibat dari persaingan jelas akan menguntungkan konsumen. Tidak ada pilihan bagi para perusahaan produsen untuk menjadikan harga sebagai salah satu andalan. Faktanya, harga murah memang selalu menjadi kunci dalam merebut pasar sekaligus basis pelanggan. Setiap perusahaan yang ada di dalam insustri popok bayi 
sekali pakai di Indonesia dipastikan memiliki jenis produk tipe ekonomis untuk dipasarkan, walaupun banyak diantaranya yang tetap mengembangkan produk tipe premium, namun dapat dipastikan permintaan tertinggi setiap tahunnya adalah merupakan jenis produk tipe ekonomis.

\begin{tabular}{|l|r|r|r|r|r|}
\hline JENIS PRODUK & $\mathbf{2 0 1 2}$ & $\mathbf{2 0 1 3}$ & $\mathbf{2 0 1 4}$ & $\mathbf{2 0 1 5}$ & $\mathbf{2 0 1 6}$ \\
\hline PREMIUM & $13 \%$ & $12 \%$ & $9 \%$ & $7 \%$ & $11 \%$ \\
\hline MEDIUM & $17 \%$ & $13 \%$ & $24 \%$ & $26 \%$ & $23 \%$ \\
\hline ECONOMIC & $70 \%$ & $76 \%$ & $67 \%$ & $66 \%$ & $65 \%$ \\
\hline & $100 \%$ & $100 \%$ & $100 \%$ & $100 \%$ & $100 \%$ \\
\hline
\end{tabular}

Sumber : Nielsen, diolah

\section{Strategi Produk}

Pada umumnya, suatu industri perlu melakukan strategi dalam hal menghasilkan produk yang berkualitas agar dapat meningkatkan keuntungan perusahaan. Suatu perusahaan tidak dapat bertahan hidup tanpa menciptakan produk yang baru. Suatu produk memiliki daur hidup tersendiri yang terdiri dari fase perkenalan (introduction), fase pertumbuhan (growth), fase kedewasaan (maturity) dan fase penurunan (decline). Masalah penurunan harus diatasi dimana perusahaan harus mempertahankan kapasitas produksi yang ada dengan dilakukannya inovasi produksi agar tidak kehilangan pangsa pasar. Cara untuk meningkatkan penjualan yaitu pertama, mengembangkan atau memperbarui produk. Mamy Poko, secara konsisten melakukan pengembangan terhadap produknya, inovasi di tahun 2016 Mamy Poko Standar yang membentuk positioning baru "Kulit Tetap Kering" dengan sepuluh jam daya serap yang dikomunikasikan lewat kemasan.
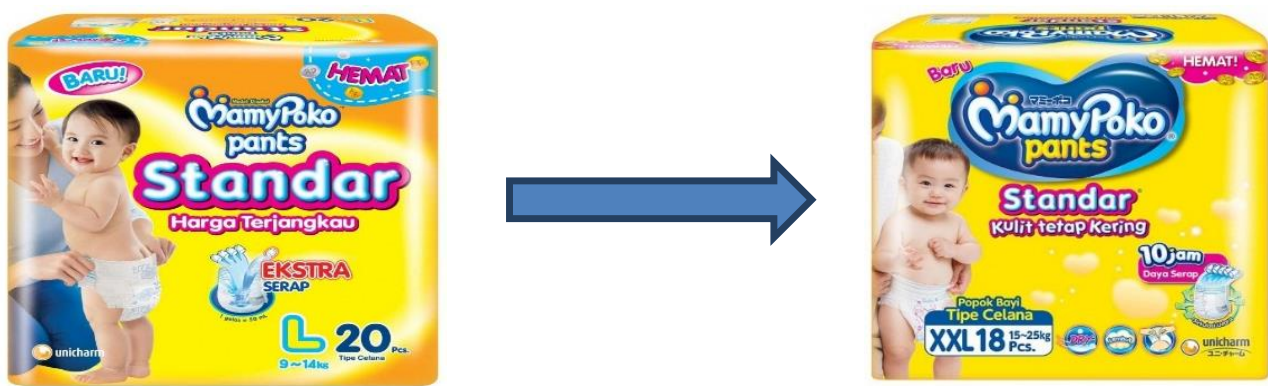

Kedua, menciptakan produk baru dari produk yang telah ada sebelumnya. Seperti yang dilakukan oleh Sweety, produk peringkat kedua di Indonesia, baru saja menambah jenis produk barunya pada awal tahun 2016, yang dinamai Sweety Gold di klaim mempunyai teknologi pertama di Indonesia yang belum pernah ada sebelumnya yaitu diamond layer technology atau teknologi dengan lapisan bertekstur berlian. Ketiga, melakukan diferensiasi produk dengan tidak hanya memproduksi satu jenis produk saja. Strategi ini dilakukan agar konsumen tidak merasa bosan dengan suatu produk.

\section{Strategi Distribusi}

Pada industri popok bayi sekali pakai, strategi distribusinya adalah Strategi Distribusi Intensif, merupakan bentuk strategi distribusi yang menempatkan produk dagangannya di banyak retailer atau pengecer serta distributor yang ada di berbagai tempat. PT. Unicharm Indonesia sebagai pemimpin pasar proses distribusi produknya secara keseluruhan melalui distributor, karena jangkauan pangsa pasar yang besar dan luas menjadikannya tidak mampu lagi ikut menangani proses pendistribusian produknya secara langsung. Sementara PT. Softex Indonesia, Kao, dan P \& G, mendistribusikan sebagian produknya secara langsung meliputi hyper and modern market sementara untuk menjangkau local modern market dan traditional market menggunakan bantuan distributor. 


\section{Strategi Promosi}

Strategi promosi dilakukan melalui Above The Line (ATL). Melalui media televisi, radio media digital serta media social. Perkembangan teknologi yang terjadi saat ini menjadikan media digital wadah yang tepat untuk melakukan kegiatan promosi bagi perusahaan. Dikombinasikan dengan strategi promosi below the line (BTL). Dengan memberikan diskon, hadiah, sponsorhip, ragam kegiatan, serta produk display.

\section{Kinerja}

\section{Pertumbuhan Industri}

Salah satu indikator yang digunakan dalam mengukur kinerja suatu industri adalah melalui pertumbuhan (growth) di dalam industri. Pertumbuhan berhubungan dengan meningkatnya output riil dari waktu ke waktu bagi produk yang dihasilkan, sehubungan dengan berbagai usaha yang dilakukan perusahaan misalnya riset dan inovasi

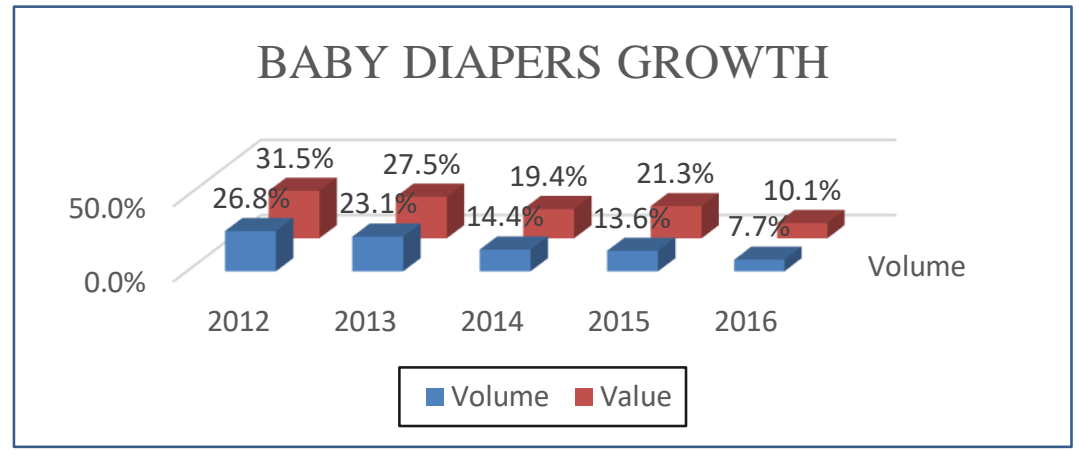

\section{Tanggung Jawab Sosial Perusahaan}

Beberapa kegiatan yang dilakukan oleh perusahaan di dalam industri popok bayi sekali pakai terkait dengan tanggung jawab sosial perusahaan, antara lain sebagai berikut :

PT. Unicharm Indonesia

- Memberi dukungan pada kegiatan seminar yang diadakan Ikatan Bidan Indonesia (IBI).

- Membuat program aktivasi Bangun Pagi Ceria.

PT. Softex Indonesia

- Membuat program Sweety Liburan Keluarga Kompak bagi keluarga Indonesia.

- Operasi bibir sumbing gratis bagi keluarga tidak mampu.

PT. Kao

- Menjalin kerja sama dengan Yayasan Cinta Anak Bangsa melalui program Anak Kao.

- Mendirikan Taman Ceria Merries.

$\underline{P \& G}$

- Pampers mengadakan acara yang bertemakan "Bayi Sehat, Ibu Bahagia"

- Membagikan 723 Pampers ke puskesmas-puskesmas di Surabaya, bertepatan dengan ulang tahun kota Surabaya yang ke-723.

\section{KESIMPULAN DAN SARAN}

\section{Kesimpulan}

- Struktur pasar industri popok bayi sekali pakai di Indonesia adalah pasar oligopoli, dengan tipe pasar perusahaan dominan.

- Perilaku pasar dalam industri popok bayi sekali pakai juga mencerminkan ciri pasar oligopoli.

- Kinerja dalam industri popok bayi sekali pakai dapat dilihat dari tingkat pertumbuhan yang terjadi di dalam industri setiap tahunnya bertumbuh sebanyak dua digit persentase. 
Struktur industri popok bayi sekali pakai adalah pasar oligopoli. Hal ini didukung dengan perilaku para pemainnya yaitu keseragaman strategi penetapan harga, tersedianya tipe produk yang sama di semua perusahaan, pemilihan saluran distribusi yang serupa, dan keseragaman tipe kegiatan promosi yang dilakukan. Struktur dan perilaku pasar juga tercermin pada kinerja para pemainnya dimana Mamy Poko sebagai pemimpin pasar sangat mempengaruhi hasil perhitungan pertumbuhan industri. Begitupun sebaliknya dengan kinerja yang lebih superior Mamy Poko dapat melakukan pengembangan produk secara intensif serta melakukan beragam kegiatan promosi yang lebih aktif dibanding pesaingnya sehingga mampu mempengaruhi struktur pasar tetap pada keadaan konsentrasi tinggi.

\section{Saran Manajerial}

- Konsolidasi diantara perusahaan

Kosolidasi yang dilakukan akan memberikan sinergi yang dapat memperbaiki kinerja perusahaan serta dapat menekan biaya perusahaan.

- Strategi pemasaran yang kreatif

Dalam erea digital saat ini, perusahaan dapat menentukan strategi pemasaran yang lebih kreatif sehingga dapat menekan biaya pemasaran dan meningkatkan marjin keuntungan.

- Struktur modal yang seimbang

Penggunaan hutang yang berlebihan untuk modal kerja akan membuat perusahaan memiliki resiko kebangkrutan yang tinggi. Perusahaan harus menyeimbangkan struktur modal sehingga keuangan perusahaan menjadi sehat, kondisi keuangan perusahaan yang sehat akan menarik bagi investor untuk berinvestasi, sehingga kebutuhan modal dapat dipenuhi melalui penyertaan modal investor tanpa harus melakukan hutang yang akan menimbulkan beban bunga.

\section{Saran untuk Peneliti Selanjutnya}

- Melakukan uji statistic

Uji statistik dapat diterapkan terhadap faktor-faktor yang mempengaruhi kinerja industri popok bayi sekali pakai di Indonesia.

- Rentang waktu yang lebih panjang

Penelitian selanjutnya dapat menggunakan rentang waktu yang lebih panjang agar grafik kinerja perusahaan dan industri secara keseluruhan terlihat secara lebih jelas.

\section{DAFTAR PUSTAKA}

Abdul Moin, Merger, Akuisisi, \& Divestasi: Edisi kedua, Yogyakarta: Ekonisia, 2010.

Alistair, A. 2004. Analisis Pendekatan Struktur-Perilaku-Kinerja pada Industri Tepung Terigu di Indonesia Pasca Penghapusan Monopoli Bulog [skripsi]. Bogor: Fakultas Ekonomi dan Manajemen, Institut Pertanian Bogor.

Badan Pusat Statistik. Pertumbuhan Penduduk. http://www.bps.go.id. Jakarta. Diakses pada tanggal 23 Juli 2017.

Badan Pusat Statistik. Proyeksi Jumlah Penduduk. http://www.bps.go.id. Jakarta. Diakses pada tanggal 23 Juli 2017.

Bain, J.S. 1956. Barriers to New Competition. Cambridge, MA: Harvard University Press.

Baye, Michael R., (2010). Managerial Economics and Business Strategy, 7th Edition. Mc Grawl-Hill, New York.

Carrol, A.B. and Buchholtz, A.K. 2006.Ethics and Stakeholder Management.7th Edition. South-Western: Cengage Learning

Case, Karl. E., \& Fair, Ray. C. (2007). Principles of Economics. Eighth Edition. New Jersey: Prentice Hall.

Dumairy. 2000. Perekonomian Indonesia, Jakarta: Erlangga. 
Greer, D.F. 1992. Industrial Public Organization and Policy. New York : Macmillan Publishing Company.

Hasibuan, N. 1993. Ekonomi Industri: Persaingan, Monopoli, dan Regulasi. LP3ES, Jakarta. Jaya, W.K., (2008), Ekonomi Industri, Edisi Kedua, BPFE, Yogyakarta.

Jaya, Wihana Kirana. 2001. Ekonomi Industri. Edisi 2. BPFE Yogyakarta.

Kartika, E. 2002. Analisis Industri Telekomunikasi Selular di Indonesia; Pendekatan Organisasi Industri [Tesis]. Depok: Magister Perencanaan dan Kebijakan Publik, Fakultas Ekonomi, Universitas Indonesia.

Keegan, Warren J. (2003). "Manajemen Pemasaran Global", Edisi keenam, penerbit: PT. Indeks Gramedia, Jakarta.

Kitab Undang-Undang Hukum Pidana (KUHP)

Kotler, Philip and Keller, Kevin Lane (2013), Manajemen Pemasaran, Edisi 13, Erlangga.

Kotler, Philip. 1997. Marketing Management Analysis, Planning, Implementation, and Control. International edition. Upper Sadle River. New Jersey: Prentice Hall Inc.

Kotler, Pihlips. Lee, Nancy. (2005). Corporate Social Responsibility. John Willey\&Sons,Inc.

Lipczynski, John, John O.S. Wilson and John Goddard. 2005. Industrial Organization: Competition, Strategy, Policy. Pearson Education Ltd, Harlow.

Lubis, Adrian \& Asmara, Alla. (2012). Analisis Struktur, Perilaku dan Kinerja Perusahaan Elektronik Setelah Pelaksanaan Liberalisasi ACFTA. Buletin Ilmiah Litbang Perdagangan, Vol.6 No.2, Desember 2012.

Mankiw Gregory, 2006 Pengantar Ekonomi Makro, Edisi Ketiga, Salemba Empat Jakarta.

Martin, S. 1993. Industrial Economics; Economic Analysis and Public Policy.

Newman, W. Lawrence. 2011. Social Research Methods: Qualitative and Quantitative Approach, 7th Edition: Pearson Education, Inc.

Pindyck, Robert.S dan Rubinfeld, Daniel.L. 2007. Mikroekonomi, Edisi Keenam, Jilid 1. PT.Indeks. Jakarta.

Samuelson, Paul A. \& William D. Nordhaus. (2004). Edisi Tujuh Belas. Ilmu Makroekonomi. Edisi Tujuh Belas, Penerbit Erlangga, Jakarta.

Scherer, F.M. 1974. Economies of Scale as a Determinant. In HJ Goldschmid, HM Mann and FW Weston (eds). Industrial Concentration : The New Learning. Boston : Little Brown and Co.pp 15-54.

Smart, D.L dan Mc.William, A. 1993. Efficiency vs structure-conductperformance: implications for strategy research and practice.http//www. business\&finance/Journal of Management/Spring,1993/Article. [17 April 2006].

Undang-Undang Larangan Praktek Monopoli dan Persaingan Usaha Tidak Sehat (UU No. 5 Tahun 1999)

Undang-Undang Perseroan Terbatas (UU No. 1 Tahun 1995)

Undang-Undang tentang Perindustrian (UU No. 5 Tahun 1984)

Undang-Undang tentang Usaha Kecil (UU No. 9 Tahun 1995) 
